\title{
Up-regulation and clinical relevance of novel helicase homologue DHX32 in colorectal cancer Chunling Huang ${ }^{\dagger}$, Xianming Liang ${ }^{\dagger}$, Ruxin Huang and Zhongying Zhang*
}

Address: Xiamen Center for Clinical Laboratory, Xiamen Zhongshan Hospital, Xiamen University, Xiamen 361004, PR China

Email: Chunling Huang - hcl_helen@hotmail.com; Xianming Liang - axming@xmzsh.com; Ruxin Huang - liang123123@sohu.com; Zhongying Zhang* - zhangzy1121@yahoo.com.cn

* Corresponding author †Equal contributors

Published: 22 January 2009

Journal of Experimental \& Clinical Cancer Research 2009, 28:II doi:10.1 I86/I756-9966-28-I I

Received: II November 2008

Accepted: 22 January 2009

This article is available from: http://www.jeccr.com/content/28/I/II

(c) 2009 Huang et al; licensee BioMed Central Ltd.

This is an Open Access article distributed under the terms of the Creative Commons Attribution License (http://creativecommons.org/licenses/by/2.0), which permits unrestricted use, distribution, and reproduction in any medium, provided the original work is properly cited.

\begin{abstract}
Background: This study aimed to find novel biomarkers for colorectal cancer.

Methods: Fluorescent mRNA differential display PCR (DD-PCR) was used to screen the genes differentially expressed in colorectal cancer tissues and their adjacent tissues. The differentially expressed genes were confirmed by real-time PCR and then their clinical relevance (such as association with tumor location and lymph gland metastasis) was further investigated.

Results: We identified by DD-PCR a novel RNA helicase, DHX32, which showed higher expression in colorectal cancer tissues than their adjacent tissues, and this result was confirmed by real time RT-PCR. In addition, we found that the level of DHX32 gene expression in colorectal cancer was significantly associated with cancer location, lymph gland metastasis, cancer nodal status, differentiation grade, and Dukes, stage.
\end{abstract}

Conclusion: DHX32 may play an important role in the development of colorectal cancer and could serve as a novel biomarker for colorectal cancer after additional investigation.

\section{Background}

Colorectal cancer (CRC) is one of the most common causes of cancer death throughout the world. Multistage development of the disease has been associated with remarkable genetic events, mainly at the level of oncogenes and oncosuppressor genes, most notably the adenomatous polyposis coli gene (APC) [1], ras [2,3], and p53 [4]. Although great advances have been made during the last few decades in understanding the molecular biology of colorectal cancer [5], the prognosis of patients with this neoplasm has not improved in parallel. The overall fiveyear survival rate remains poor (40-45\%) [6]. It can be assumed that several genes involved in the pathogenesis of colorectal cancer are still unknown. Therefore, further elucidation of the molecular biology of colorectal cancer may be useful to devise new methods for the diagnosis and the treatment of the disease.

Several approaches have been taken to identify and compare gene expression in normal and disease states [7-11]. The differential display technique was employed in this study based on its ability to identify both up-regulated genes (putative oncogenes) and down-regulated genes (putative tumor/metastasis suppressor genes) simultaneously. Differential Display (DD) is a useful method to compare patterns of gene expression in RNA samples of different types or under different biological conditions $[8,9]$. The technique produces partial cDNA fragments by 
a combination of reverse transcription (RT) and PCR of randomly primed RNA. Changes in the expression level of genes are identified after separation of the cDNA fragments produced in an arbitrarily primed polymerase chain reaction on a sequencing-type gel. When combined with real-time quantitative PCR to eliminate false positives, DD becomes a powerful method for generating high confidence hits in the screening of hundreds of potentially differentially expressed transcripts. A number of genes such as UCC1 [12], Reg [13], and PIGR [14] have been detected by DD-PCR to be associated with colorectal cancer.

In this study, we found that $D H X 32$, a novel RNA helicase, was significantly up-regulated in colorectal cancer compared to its adjacent normal tissue using a combination of DD-PCR and real-time PCR methods. Our results suggested that the level of DHX32 gene expression in colorectal cancer was significantly associated with cancer location, lymph gland metastasis, cancer nodal status, differentiation grade and Dukes' stage.

\section{Methods \\ Subjects}

34 pairs of specimens (tumor tissues and their adjacent normal tissues) and 14 tumor tissues were obtained from patients with colorectal cancer who underwent surgical resection at the Xiamen Zhongshan Hospital, Xiamen University in Xiamen during 2006 and 2007. The detail clinical and pathological characteristics of these 48 cases of samples were listed in a table 1 . Adjacent normal tissues were defined as tissues which have no sign of cancer by visual inspection and which were located $3-5 \mathrm{~cm}$ surrounding the boundary of the cancer tissues. All of the patients gave informed consent prior to surgery. All specimens were reevaluated by a pathologist in the hospital. The specimens for assay were snap-frozen and stored in liquid nitrogen until analysis.

\section{RNA extraction and CDNA synthesis}

Total RNA was prepared using Trizol reagent (Invitrogen, California, USA) according to the manufacturer's instructions. RNA was treated with DNase? (Invitrogen, California, USA) in the presence of $50 \mu \mathrm{M}$ T7(dT12)AP2, T7(dT12)AP7 primer in $20 \mu \mathrm{l}$ RT buffer $(1 \times$ PCR buffer, 10 $\mathrm{mM}$ DTT, $0.25 \mathrm{mM} \mathrm{dNTP),} \mathrm{at} 25^{\circ} \mathrm{C}$ for 5 minutes, followed by $42^{\circ} \mathrm{C}$ for 10 minutes and $50^{\circ} \mathrm{C}$ for 60 minutes. Reverse transcriptase was inactivated at $70^{\circ} \mathrm{C}$ for $15 \mathrm{~min}$ utes.

\section{Differential display}

Differential display was performed using Hieroglyph mRNA Profile kit (Beckman, California, USA). Briefly, PCR amplification was done using $1.5 \mu \mathrm{l}$ of the cDNA, primed with arbitrary $\mathrm{P}$ primer and anchored $\mathrm{T}$ primer.
Table I: Patients characteristics $(n=48)$

\begin{tabular}{|c|c|}
\hline & n (\%) \\
\hline \multicolumn{2}{|l|}{ Age (year) } \\
\hline$<59$ & $25(52.1)$ \\
\hline$\geq 59$ & $23(47.9)$ \\
\hline \multicolumn{2}{|l|}{ Gender } \\
\hline Male & $22(45.8)$ \\
\hline Female & $26(54.2)$ \\
\hline \multicolumn{2}{|l|}{ Tumor Location } \\
\hline Colon & $10(20.8)$ \\
\hline Rectum & $38(79.2)$ \\
\hline \multicolumn{2}{|l|}{ Polypi } \\
\hline+ & |4(29.2) \\
\hline- & $34(70.8)$ \\
\hline \multicolumn{2}{|l|}{ Lymph metastases } \\
\hline+ & $27(56.3)$ \\
\hline- & $21(43.7)$ \\
\hline \multicolumn{2}{|l|}{ Tumor Nodal } \\
\hline+ & $20(4 I .7)$ \\
\hline- & $28(58.3)$ \\
\hline \multicolumn{2}{|l|}{ Tumor Differentiation } \\
\hline Poor & $9(18.8)$ \\
\hline Median + WELL & $39(81.2)$ \\
\hline \multicolumn{2}{|l|}{ Dukes, Stage } \\
\hline$A+B$ & $2 I(43.8)$ \\
\hline$C+D$ & $27(56.2)$ \\
\hline
\end{tabular}

Amplification at $\left(95^{\circ} \mathrm{C} 2\right.$ minutes) 1 cycle, $\left(94^{\circ} \mathrm{C}\right.$ for 15 seconds, $50^{\circ} \mathrm{C}$ for 60 seconds, $72^{\circ} \mathrm{C}$ for 2 minutes) 4 cycles, $\left(94^{\circ} \mathrm{C}\right.$ for 15 seconds, $60^{\circ} \mathrm{C}$ for 30 seconds, $72^{\circ} \mathrm{C}$ for 2 minutes) 25 cycles, followed by a final extension at $72^{\circ} \mathrm{C}$ for 7 minutes on a GeneAmp PCR system 9600 (Perkin-Elmer, Norwalk, USA). Following amplification of randomly primed mRNAs by RT-PCR, the CDNA products were heated at $94^{\circ} \mathrm{C}$ for 2 minutes and separated on a denaturing 5.6\% polyacrylamide gel using a Genomyx LR DNA Sequencer (Beckman, California, USA). Bands exclusively present in either of two samples were considered as candidates of differentially expressed transcripts, which were excised, eluted, re-amplified, and subcloned into the pGEM-T easy vector (Promega, Madison, USA). The sequence reactions were performed by Invitrogen Corp (California, USA). Sequence homology to published database was analyzed with the BLAST program at the internet site of NCBI (National Center for Biotechnology Information) http://www.ncbi.nlm.nih.gov/blast/blast.cgi. 


\section{Real-time quantitative reverse transcription polymerase chain reaction}

We measured DHX32 expression in 48 tumor samples by real-time quantitative RT-PCR using TaqMan methodology in an ABI PRISM 7500 Sequence Detection System. The real-time RT-PCR allows, by means of fluorescence emission, the identification of the cycling point when PCR product is detectable. The Ct value inversely correlates with the starting quantity of target mRNA. Measurements were performed in duplicate and the controls were included in which the reaction mixture contained no cDNA. The amount of target mRNA after normalized to the endogenous reference $\beta$-actin was calculated by the $\mathrm{Ct}$ method as described by Liu W [15].

Primers and probes for $\beta$-actin and DHX32 mRNAs were chosen using the Primer Express 2.0 software (Applied Biosystems, Foster City, USA). The primers, placed in different exons, were designed to ensure that genomic DNA would not be amplified. Primer and probe nucleotide sequences for DHX32 (GenBank accession number NM 018180) were: DHX32-Fw 5'-GTCTTTCCATCCACTACCAGCAC-3', DHX32-Rev 5'-ATGATGACCCCATAGCT ACCCAA-3', and TaqMan probe 5'-(FAM) CGTGATATGCACACAGGTCCACAAG C (TAMRA)-3'. Primers and probe for $\beta$-actin mRNA were: $\beta$-actin-Fw $5^{\prime}$ TCACCCACACTGTGCCCATCTACGA-3', $\beta$-actin-Rev $5 '$ CAGCGGAACCGCTCATTGCCAATGG-3', and TaqMan probe 5'-(FAM)ATGCCC-X(TAMRA)-CCCCCATGCCATCCTGCGT-3'. Probes were purchased from Invitrogen Corp (Invitrogen, California, USA). The thermal cycling conditions were: 5 minutes at $95^{\circ} \mathrm{C}$, followed by 60 cycles of 30 seconds at $95^{\circ} \mathrm{C}$ and 1 minute at $60^{\circ} \mathrm{C}$.

\section{Statistic analysis}

The Levene's test was performed to determine the homogeneity of variance for all the data, and then the paired Chi-Square test or 2-related samples Wilcoxon nonparametric test was performed to compare the positive rates and the levels of DHX32 gene expression between tumor tissue and its adjacent normal tissue in each patient, respectively. The Mann-Whitney U test was used for comparing the gene expression of DHX32 between the different groups according to various clinical and pathological variables. All of the statistical analyses were performed with SPSS 14.0 (Chicago, USA). A P value of less than 0.05 was considered to be statistically significant.

\section{Results}

Identification of a gene differentially expressed in the colorectal tumor and the adjacent normal tissue using DDPCR

The modified DD-PCR method was used to identify genes uniquely and/or highly expressed in human CRC tissues by comparing with those in adjacent normal tissues. One
cDNA band (size ranging between 700 bp and 800 bp) was found to be highly expressed in colorectal cancer tissues while barely expressed in matched adjacent normal tissues. The identified band was recovered, re-amplified, subcloned and sequenced. BLAST analysis of this nucleotide sequence revealed $99 \%$ homology to the gene DHX32 in the GenBank database.

\section{Confirmation of DHX32 differently expressed in colorectal tumors (CT) and their adjacent normal tissues (ANT) by real-time $P C R$}

We compared both positive rate and gene expression level in order to confirm the difference of DHX32 gene expression between colorectal tumors and their adjacent normal tissues. We found that the positive rate of DHX32 gene expression was significantly higher in the colorectal tumors $(76.5 \%)$ than that in the adjacent normal tissues (26.4\%) (Table 2). Consistent with the higher positive rate of DHX32 gene expression in the colorectal tumors, its gene expression level was also significantly higher than that in the adjacent normal tissues (Figure 1). In addition, the distribution of the patients with decreased, constant or increased gene expression of DHX32 was also analyzed. Whether it was decreased, constant or increased expression for each patient was arbitrarily classified according to the gene expression ratios between the tumor tissue and its adjacent normal tissue in each patient as described in the literature [16]: decreased expression $(<0.8)$, constant expression $(0.8 \sim 1.2)$, increased expression $(>1.2)$. Tumor tissues from $58.8 \%$ of the patients displayed increased

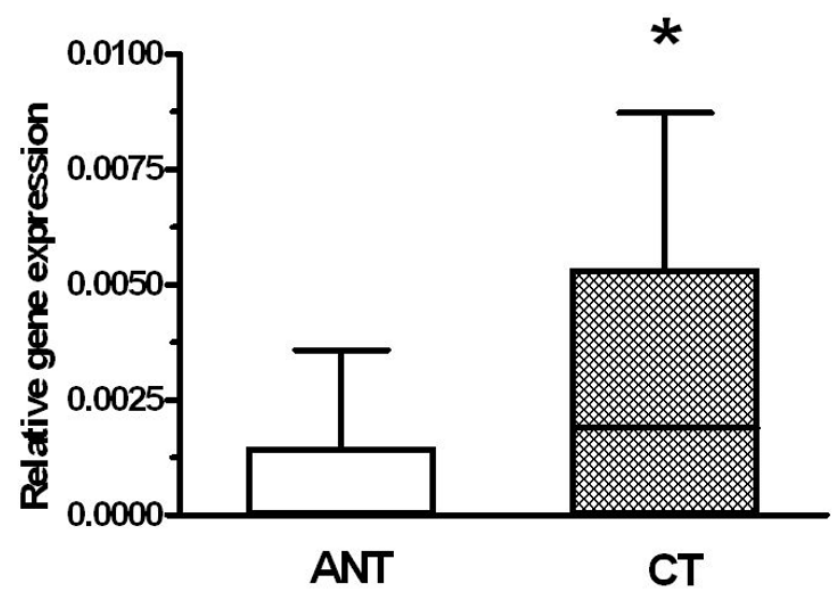

Figure I

Comparison of $D H X 32$ gene expression between colorectal tumors (CT) and their adjacent normal tissues (ANT) DHX32 gene expression in colorectal tumors was significantly higher than that in their adjacent normal tissues. Data were expressed with Box \& Whiskers. ANT: Adjacent normal tissue; CT: Cancer tissues. $*: P<0.05$. 
Table 2: The positive rate of $D H X 32$ gene expression in the colorectal tumors and adjacent normal tissues

\begin{tabular}{cllc}
\hline Group & \multicolumn{1}{c}{ DHX32 gene expression+ } & Positive rate \\
\cline { 2 - 3 } & + & - & \\
\hline Tumor tissue & 26 & 8 & $76.5 \% *$ \\
Adjacent normal tissue & 9 & 25 & $26.4 \%$ \\
\hline
\end{tabular}

$*: P<0.01$

gene expression of DHX32. Those from $29.4 \%$ of the patients did not change and those from $11.8 \%$ of the patients even showed decreased gene expression of DHX32 (Table 3).

\section{Relationships between DHX32 gene expression and clinically pathological parameters}

In order to determine the relationships between DHX32 gene expression and the clinical-pathological parameters (age, gender, tumor location, Polypi, lymph metastases, nodal status, differentiation grade, and Dukes' stage), we compared the positive rate and the levels of DHX32 gene expression between the different groups according to various clinical and pathological variables. Although we did not observe significant differences of the positive rate of DHX32 gene expression between the groups according to each parameter (data not shown), our results suggested that the level of DHX32 gene expression in colorectal carcinoma was significantly associated with tumor location, lymph gland metastasis, tumor nodal status, differentiation grade and Dukes' stage $(\mathrm{P}<0.05)$ (Figure 2$)$. There were no apparent differences of $\mathrm{DHX} 32$ gene expression between the different groups classified by age, gender, and Polypi.

\section{Discussion}

The study of the molecular biology of colorectal cancer has progressed rapidly, but the survival of patients with this neoplasm has improved rather modestly [17]. Consequently, further studies of CRC-related genes would help better understand the tumorigenesis of CRC and develop new methods for population screening, follow-up of treated patients, prognosis, and new therapies of the disease. In this study, we demonstrated that human DHX32,

Table 3: DHX32 gene expression in the colorectal tumors and their adjacent normal tissues

\begin{tabular}{lccc}
\hline & \multicolumn{3}{c}{ Gene expression of $\mathrm{DHX32}(\mathrm{CT} / \mathrm{ANT}, \mathrm{n}=34)$} \\
\cline { 2 - 4 } & $<0.8$ & $0.8 \sim 1.2$ & $>1.2$ \\
\hline Patients & $4(11.8 \%)$ & $10(29.4 \%)$ & $20(58.8 \%)$
\end{tabular}

I. CT (+) and ANT (-) treated as >1.2; 2. CT (-) and ANT (+) treated as $<0.8$; 3. CT (-) and ANT (-) treated as I. a novel RNA helicase, was up-regulated in colorectal cancer compared to its adjacent normal tissues. Furthermore, our results suggested that the level of DHX32 gene expression in colorectal carcinoma was significantly associated with tumor location, lymph gland metastasis, tumor nodal status, differentiation grade, and Dukes' stage.

DHX32 was originally identified as a novel RNA helicase with unique structure in the helicase domain, but with overall similarity to the DHX family of helicases [18]. RNA helicases are enzymes that utilize the energy derived from nucleotide triphosphate (NTP) hydrolysis to modulate the structure of RNA molecules and thus potentially influence all biochemical steps involving RNA which at least include transcription, splicing, transport, translation, decay, and ribosome biogenesis $[19,20]$. The involvement of RNA molecules in these steps is influenced by their tendency to form secondary structures and by their interaction with other RNA molecules and proteins [21]. DHX32 is composed of 12 exons spanning a $60-\mathrm{kb}$ region at human chromosome 10q26 and encodes for a 743 amino acid protein with a predicted molecular weight of 84.4 $\mathrm{kDa}$. DHX32 has a widespread tissue distribution and also has cross-species counterparts, such as 84 and $80 \%$ amino acid identity with mouse and rat counterparts, respectively. The high level of similarity between human and murine DHX32 and the widespread expression of DHX32 message suggest that it is an evolutionally conserved and functionally important gene.

With a few notable exceptions, the biochemical activities and biological roles of RNA helicases, including DHX32, are not very well characterized. In our study, we found that DHX32 was overexpressed in colorectal cancer compared with the adjacent normal tissues, suggesting that abnormal expression of DHX32 is associated with the development of colorectal cancer. The involvement of DHX32 in other cancer development was previously demonstrated by other groups. For example, the expression of DHX32 was dysregulated in several lymphoid malignancies $[18,22]$. DHX32 was reported as anti-sense to another gene, BCCIP (BRCA2 and CDKN1A Interacting Protein), and BCCIP was down-regulated in kidney tumors [23]. The overexpression of one of BCCIP isoforms can inhibit tumor growth [24].

So far, several groups have attempted to reveal the underlying mechanisms by which DHX32 involves in cancer development, but the exact biochemical activities and biological functions of DHX32 are still elusive. DHX32 contains sequences which are highly conserved between a subfamily of DEAH RNA helicases, including the yeast pre-mRNA splicing factor Prp43 [25], and its mammalian ortholog DHX15. The structural similarity of DHX32 to RNA helicases involved in mRNA splicing suggests a role 

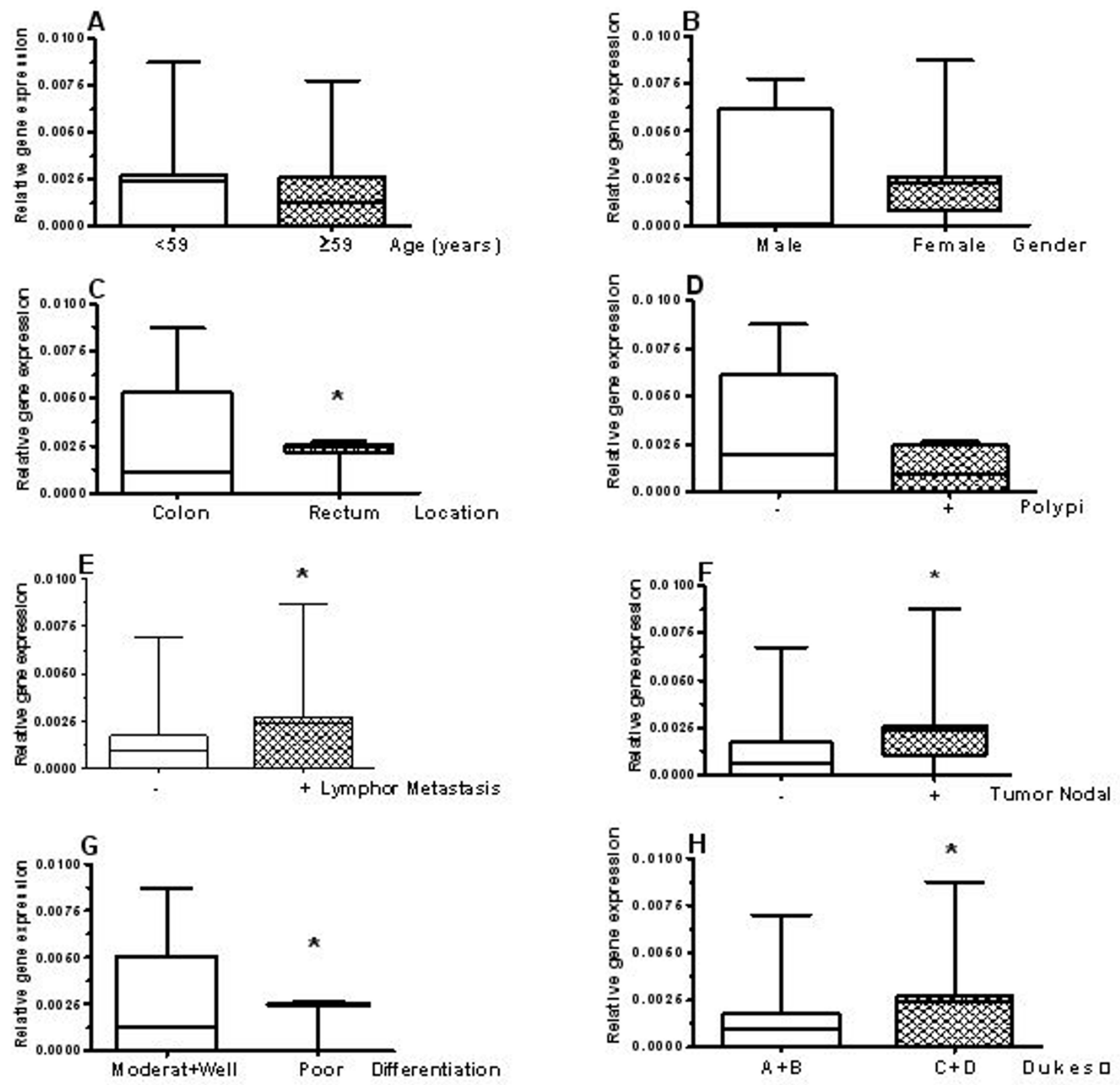

Figure 2

The relationships between $\mathrm{DHX} 32$ gene expression and the clinical-pathological parameters (age, gender, tumor location, Polypi, lymph metastases, nodal status, differentiation grade and Dukes, stage) $D H X 32$ gene expression in colorectal carcinoma was not significantly associated with age (A), gender (B) and Polypi (D), but associated with tumor location (C), lymph gland metastasis (E), tumor nodal Status (F), differentiation grade (G) and Dukes, stage (H). Data were expressed with Box \& Whiskers. *: $P<0.05$.

in pre-mRNA splicing. It is possible that the dysregulation of the normal function of RNA helicases can potentially result in abnormal RNA processing with deleterious effects on the expression/function of key proteins in normal cell cycles and contribute to cancer development and/ or progression. There are several examples of dyregulation of RNA helicases in cancer [26], mostly in the forms of overexpression including those of DDX5 [27] and DDX6 [28] which were reported to be overexpressed in colorectal tumor. 
Our results indicated that the differential expression of DHX32 in colorectal carcinoma was significantly associated with tumor location, lymph gland metastasis, tumor nodal status, differentiation grade, and Dukes' stage. These results not only further confirmed the possible critical role of DHX32 in human colorectal development, but also suggested that additional studies may help develop DHX32 as a potential biomarker to judge the prognosis of colorectal cancer patients: the patients with higher gene expression of DHX32 may have worse prognosis.

In conclusion, to our knowledge, we are the first to report the more frequent and significant overexpression of human DHX32 in human CRC than that of the adjacent normal tissue, indicating that overexpression of DHX32 may play a pivotal role in the multistage carcinogenesis of human CRC. It still remains to be further investigated for the functions of DHX32 during the progression of colorectal cancer. DHX32 may also serve as a bio-marker for judging the levels of malignancy of colorectal cancer, which may guide the development of anticancer therapy regime after additional studies.

\section{Conclusion}

DHX32 may play an important role in the development of colorectal cancer and additional studies may help use DHX32 as a novel biomarker for colorectal cancer.

\section{Competing interests}

The authors declare that they have no financial competing interests.

\section{Authors' contributions}

$\mathrm{ZZ}$ conceived of the study and guided the biochemical experiments.

\section{CH performed DD-PCR and drafted the manuscript.}

XL performed real-time PCR, analyzed data, collected tissue specimens and clinical records, and helped write the manuscript.

RH conceived of the idea and provided helpful comments.

All authors read and approved the final manuscript.

\section{Acknowledgements}

This study was funded by Xiamen Bureau for Science and Technology (No.A0000033).

\section{References}

I. Samowitz WS, Slattery ML, Sweeney C, Herrick J, Wolff RK, Albertsen H: APC mutations and other genetic and epigenetic changes in colon cancer. Mol Cancer Res 2007, 5:165-170.

2. Keller JW, Franklin JL, Graves-Deal R, Friedman DB, Whitwell CW, Coffey RJ: Oncogenic KRAS provides a uniquely powerful and variable oncogenic contribution among RAS family members in the colonic epithelium. J Cell Physiol 2007, 21 0:740-749.

3. Haigis KM, Kendall KR, Wang Y, Cheung A, Haigis MC, Glickman JN, Niwa-Kawakita M, Sweet-Cordero A, Sebolt-Leopold J, Shannon KM, Settleman J, Giovannini M, Jacks T: Differential effects of oncogenic K-Ras and N-Ras on proliferation, differentiation and tumor progression in the colon. Nat Genet 2008, 40:600-608.

4. Samowitz WS: Genetic and epigenetic changes in colon cancer. Exp Mol Pathol 2008, 85:64-67.

5. Benito M, Diaz-Rubio E: Molecular biology in colorectal cancer. Clin Transl Oncol 2006, 8:391-398.

6. Khair G, Monson JR, Greenman J: Epithelial molecular markers in the peripheral blood of patients with colorectal cancer. Dis Colon Rectum 2007, 50: I 188-1 203.

7. Okubo K, Hori N, Matoba R, Niiyama T, Fukushima A, Kojima Y, Matsubara $K$ : Large scale cDNA sequencing for analysis of quantitative and qualitative aspects of gene expression. Nat Genet 1992, 2: 173-179.

8. Liang P, Pardee AB: Differential display of eukaryotic messenger RNA by means of the polymerase chain reaction. Science 1992, 257:967-97।.

9. Welsh J, Chada K, Dalal SS, Cheng R, Ralph D, McClelland M: Arbitrarily primed PCR fingerprinting of RNA. Nucleic Acids Res 1992, 20:4965-4970.

10. Lisitsyn N, Lisitsyn N, Wigler M: Cloning the differences between two complex genomes. Science 1993, 259:946-95I.

II. Velculescu VE, Zhang L, Vogelstein B, Kinzler KW: Serial analysis of gene expression. Science 1995, 270:484-487.

12. Nimmrich I, Erdmann S, Melchers U, Chtarbova S, Finke U, Hentsch S, Hoffmann I, Oertel M, Hoffmann W, Muller O: The novel ependymin related gene $\mathrm{UCCl}$ is highly expressed in colorectal tumor cells. Cancer Lett 200I, 165:7I-79.

13. Violette S, Festor E, Pandrea-Vasile I, Mitchell V, Adida C, Dussaulx E, Lacorte JM, Chambaz J, Lacasa M, Lesuffleur T: Reg IV, a new member of the regenerating gene family, is overexpressed in colorectal carcinomas. Int J Cancer 2003, 103:185-193.

14. Traicoff JL, De Marchis L, Ginsburg BL, Zamora RE, Khattar NH, Blanch VJ, Plummer S, Bargo SA, Templeton DJ, Casey G, Kaetzel CS: Characterization of the human polymeric immunoglobulin receptor (PIGR) 3'UTR and differential expression of PIGR mRNA during colon tumorigenesis. J Biomed Sci 2003, 10:792-804

15. Liu W, Saint DA: A new quantitative method of real time reverse transcription polymerase chain reaction assay based on simulation of polymerase chain reaction kinetics. Anal Biochem 2002, 302:52-59.

16. Truant SC, Gouyer VP, Leteurtre EA, Zerimech F, Huet GM, Pruvot FR: E-Cadherin and beta-Catenin mRNA Levels Throughout Colon Cancer Progression. J Surg Res 2008, 150:21 2-218.

17. Hoops TC, Traber PG: Molecular pathogenesis of colorectal cancer. Hematol Oncol Clin North Am 1997, I I:609-633.

18. Abdelhaleem M: The novel helicase homologue DDX32 is down-regulated in acute lymphoblastic leukemia. Leuk Res 2002, 26:945-954.

19. Tanner NK, Linder P: DExD/H box RNA helicases: from generic motors to specific dissociation functions. Mol Cell 200I, 8:25I-262.

20. de la CJ, Kressler D, Linder P: Unwinding RNA in Saccharomyces cerevisiae: DEAD-box proteins and related families. Trends Biochem Sci 1999, 24:192-198.

21. Velden AW van der, Thomas AA: The role of the 5 ' untranslated region of an $\mathrm{mRNA}$ in translation regulation during development. Int J Biochem Cell Biol 1999, 31:87-106.

22. Alli Z, Ho M, Abdelhaleem M: Expression of DHX32 in lymphoid tissues. Exp Mol Pathol 2005, 79:21 9-223.

23. Meng X, Liu J, Shen Z: Genomic structure of the human BCCIP gene and its expression in cancer. Gene 2003, 302:139-| 46.

24. Liu J, Yuan Y, Huan J, Shen Z: Inhibition of breast and brain cancer cell growth by BCCIPalpha, an evolutionarily conserved nuclear protein that interacts with BRCA2. Oncogene 200I, 20:336-345

25. Martin A, Schneider S, Schwer B: Prp43 is an essential RNAdependent ATPase required for release of lariat-intron from the spliceosome. J Biol Chem 2002, 277:17743-17750.

26. Abdelhaleem M: Do human RNA helicases have a role in cancer? Biochim Biophys Acta 2004, I 704:37-46. 
27. Causevic M, Hislop RG, Kernohan NM, Carey FA, Kay RA, Steele RJ, Fuller-Pace FV: Overexpression and poly-ubiquitylation of the DEAD-box RNA helicase $\mathbf{6 8} 8$ in colorectal tumours. Oncogene 200I, 20:7734-7743.

28. Hashimoto K, Nakagawa Y, Morikawa H, Niki M, Egashira Y, Hirata I, Katsu K, Akao Y: Co-overexpression of DEAD box protein rck/ p54 and c-myc protein in human colorectal adenomas and the relevance of their expression in cultured cell lines. Carcinogenesis 200I, 22: 1965-1970.

Publish with Biomed Central and every scientist can read your work free of charge

"BioMed Central will be the most significant development for disseminating the results of biomedical research in our lifetime."

Sir Paul Nurse, Cancer Research UK

Your research papers will be:

- available free of charge to the entire biomedical community

- peer reviewed and published immediately upon acceptance

- cited in PubMed and archived on PubMed Central

- yours - you keep the copyright 